\title{
Level of Awareness and Practices of Women Regarding Breast Cancer in Chhattisgarh, India: An Institution Based Survey
}

\author{
Sunita Singh ${ }^{1,{ }^{*}}$, Anjali Pal ${ }^{2}$, Niraj Kumar Srivastava ${ }^{3}$, Pushpawati Thakur ${ }^{4}$
}

Sunita Singh ${ }^{1, *}$, Anjali Pal', Niraj Kumar Srivastava ${ }^{3}$, Pushpawati Thakur ${ }^{4}$

\section{'Department of Surgery, All India} Institute of Medical Sciences (AIIMS), Raipur, Chhattisgarh, 492099, INDIA. ${ }^{2}$ Department of Community and Family Medicine, All India Institute of Medical Sciences, Raipur, Chhattisgarh, 492099, INDIA.

${ }^{3}$ Department of Trauma and

Emergency, All India Institute of Medical Sciences, Raipur, Chhattisgarh, 492006, INDIA.

${ }^{4}$ Department of Obstratics and Gynaecology, All India Institute of Medical Sciences, Chhattisgarh, 492099, INDIA.

\section{Correspondence}

\section{Dr. Sunita Singh}

Associate Professor, Department of Pediatric Surgery, All India Institute of Medical Sciences, Raipur, Chhattisgarh, 492099, INDIA.

Phone no: 8518881733

Email: drsunitasingh28@gmail.com

\section{History}

- Submission Date: 12-07-2018

- Revised Date: 04-10-2018

- Accepted Date: 16-11-2018

DOI : 10.5530/ijmedph.2018.4.30

Article Available online

http://www.ijmedph.org/v8/i4

\section{Copyright}

(C) 2018 Phcog.Net. This is an openaccess article distributed under the terms of the Creative Commons Attribution 4.0 International license.

\begin{abstract}
Objective: To study the knowledge, attitude and practices of breast cancer among the women of Chhattisgarh for identifying their knowledge gaps about breast cancer symptoms, risk factor and screening methods. Methods: (i) Design: Cross sectional descriptive study. (ii) Setting: Women registered outdoor clinics of surgery department of a Medical College and Hospital, from Sep 2016 to March 2017. (iii) Sample Size: Participants number was 500. (iv) Participants: Women > 18 yrs except those suffering from breast cancer. (iv) Main outcome variables: level of breast cancer knowledge, source of knowledge and correlation of knowledge with participant demography. Conclusion: There were wide knowledge gap for breast cancer symptoms, risk factor and screening methods in women. The lack of knowledge about symptoms, risk factor and screening methods cause delay in the diagnosis of breast cancer. Clinical breast examination by health care personnel (doctors, nurses, multipurpose health worker) in women > $35 \mathrm{yrs}$; and training for breast self-examination can be introduced as a mandatory policy for women attending out door clinics.

Key words: Breast cancer awareness, Breast self-examination, Knowledge attitude behavior and practices for breast cancer, KAP Survey Breast Cancer, KAPB survey on breast cancer India.
\end{abstract}

\section{INTRODUCTION}

The breast cancer is the most common cancer diagnosed in females both in developed and developing regions. ${ }^{1,2}$ The breast cancer is the leading cause of cancer deaths in females (GLOBOCON 2012). ${ }^{1,2}$ Each year, $55-60 \%$ of all new breast cancer diagnosed globally and $62-70 \%$ of breast cancer deaths occur in low- and middle-income countries (2010). ${ }^{2,3}$ In India breast cancer is responsible for $19-34 \%$ of all malignant cases (Population and hospital based National Cancer registery 2012-2014).,2,4 The agestandardised incidence rates in India are lower as compared to the United Kingdom (UK) (25.8 versus 95 per 100,000 in 2010, GLOBOCON). ${ }^{1,2}$ However mortality rate is comparable (12.7 vs 17.1 per 100,000 ) with United Kingdom (International Agency for Cancer Research, 2012). ${ }^{5}$ In India most common cause of high mortality is diagnosis of breast cancer at advanced stages. ${ }^{4,6}$ The contributing factors for detection of breast cancer at advance stages are poor awareness, tardy and bothersome referral pathways, inadequate accessibility to proper diagnosis and treatment at cancer centers, almost non-existent breast cancer screening programs, women concern about body image, prevalent myths and cultural taboos. ${ }^{4,7}$ The other factors leading to high mortality are incomplete therapy regimens, non-compliance of treatment, distrust in health system..$^{9-11}$ In developing countries the average age at diagnosis is 10 years lesser than women in Western countries. ${ }^{10}$

Government of India had launched National Cancer Control Program (1975), under the $12^{\text {th }}$ five year Plan (2012- 2017) to increase awareness and early detection behaviors for various diseases including cancer. ${ }^{12}$ This KAP survey was planned to assess the existing level of awareness of breast cancer at Chhattisgarh to plan further strategy at our hospital for early detection of breast cancer.

\section{MATERIAL AND METHODS}

This was a cross-sectional descriptive study conducted at the outdoor Department of Surgery of Medical college and hospital from 2016. The study was carried out after obtaining approval from the institutional ethical committee. The target group was women 16-65 yrs of age (other than known case of breast cancer).

Information was collected on the demographic profile, educational level, occupation status and socioeconomic status (Modified B.G. Prasad 2016). ${ }^{13}$ The study participants were provided a self-administered questionnaire with due assistance in filling the questionnaire. The questionnaire was verified by expert in Hindi literature and English literature. The questionnaire was to assess the basic knowledge of breast cancer symptoms, risk factors, preventive measures,
Cite this article : Singh S, Pal A, Srivastava NK, Thakur P. Level of Awareness and Practices of Women Regarding Breast Cancer in Chhattisgarh, India: An Institution Based Survey. Int J Med Public Health. 2018;8(4):145-51. 
common misconceptions and early detection methods. We enquired about definitive risk factor as described by an expert panel committee of the International Agency for Research on Cancer (IARC), the World Cancer Research Fund (WCRF) and the American Institute of Cancer Research (AICR) (see Table 1). ${ }^{14-16}$ Information was collected on age, family history, age at first birth, parity, duration of breastfeeding, obesity, alcohol use, tobacco use, menstrual history etc.,. The oral contraceptive pills and hormone replacement therapy as a risk factor were not incorporated because of substantial heterogenecity. ${ }^{16,17}$ This was followed by breast cancer awareness education/ interactive session. The session incorporated education about breast cancer symptoms, risk factor, breast self-examination (BSE), clinical breast examination (CBE) and mammography. The interaction session was to clear myths about breast cancer and performance of clinical breast examination by clinician, training of BSE and distribution of education material.

Self-made scoring for awareness was done on 45 points for 45 responses in the questionnaire (see Annexure 1). One point was given for correct response and no point for wrong or don't know response. The level of breast cancer awareness was defined as poor awareness (score 0-15), average (score 16-30), good awareness (score 31-45) (see Table 2).

\section{Statistical analysis}

The data were entered in MS Excel sheet and analysis was done using Statistical Package for Social Sciences (SPSS) Version 11. Chi square test was applied to test the difference in awareness level by age, occupation, socio economic status and education.

\section{RESULTS}

From September 2016 to March 2017, 1200 women (excluding known case of breast cancer) were asked to participate in the survey. Only 1000 women (response rate $83.33 \%$ ) gave consent. The data analysis was done for randomly selected 495 survey questionnaires. The mean age of the

\begin{tabular}{|c|c|}
\hline Socioeconomic class & Per Capita family Income \\
\hline Upper Class & $\geq$ Rs. 6346 \\
\hline Upper Middle Class & Rs. $3173-6345$ \\
\hline Lower Middle Class & Rs.1904- 3172 \\
\hline Upper Lower Class & Rs.952-1903 \\
\hline Lower Class & Rs. $\leq 952$ \\
\hline
\end{tabular}

women was 35.17 years (range 16-65 years). The demographic profile of participant is shown in Figure 1. Majority (30.0 \%) of women were in the age group of 26-35 years. The married women were $36.96(\mathrm{n}=181)$ $\%$ and $34.94 \%(\mathrm{n}=173)$ women belongs to rural area. The maximum participants in the study were housewives. Illiteracy rate of women in the study was 7.9\%. According to Modified BG Prasad's (2016) $71.31 \%$ $(\mathrm{n}=353)$ were in upper class.

Most of the women were aware of breast cancer relationship with family history of breast cancer (50.5\%) and previous radiation exposure (68.2\%) to breast. Their knowledge of the influence of lifestyle, dietary habits, alcohol intake and personal reproductive and menstrual history as a risk factor for breast cancer were poor. More than $50 \%$ were aware of genetic factor as risk factor for breast cancer. Wearing brassier (60.2\%), physical trauma or repeated infection in the breast (58.58\%) and stressful lifestyle (39.39\%), were wrongly identified risk factors for breast cancer (see Table 3).

Around $34.14 \%$ women identified painless breast lump as a symptom of breast cancer. Around 39\% women identified an ulcer over the breast and increase in size of breast as the only symptom of breast cancer. The response rate for skin texture change, colour change, nipple changes were subtle (see Table 3 ). None of the participant were aware that lump in the axilla can be related to breast cancer. None of the participant was aware of all symptoms of breast cancer.

Although 19\% women had heard about breast self-examination (BSE), but only $10.10 \%$ of women perform BSE and none of them know the correct method and recommended frequency of BSE. Most of the women agree that regular clinical breast examination $(\mathrm{CBE})$ is the most important method for early detection of breast cancer. But none of them were aware of recommended frequency and age for the CBE. Only 5.50\% women knew about mammography, these were women who consulted for breast pain and underwent screening mammography.

About 19\% (95/495) of women have Good Breast cancer awareness. Twenty one percent have average awareness while more than half (60\%) have poor awareness (see Figure 2). The print media (magazine and newspaper) is the most common source of providing information about breast cancer to the participants. On enquiring about the preferred mode of receiving information regarding breast cancer, social media and television were preferred by urban women and frequent health camps or personnel information by health care provider by rural women.

No significant association was observed between awareness and age. However, participant scored good level of knowledge of breast cancer were maximum in number within $18-35$ year $(58.9 \%, n=56 / 95)$. The

\begin{tabular}{|c|c|c|}
\hline Sufficient/convincing evidence & Insufficient / weak evidence & No. conclusive evidence \\
\hline Increase risk & Increase risk & \\
\hline Alcohol consumption & Total dietary fat & Meat \\
\hline Body fatness (post-menopausal) & Greater birth weight (pre-menopausal) & Fish \\
\hline Adult height (post-menopausal) & Tobacco smoking & Folate \\
\hline Any use of oral contraceptive pills (OCP) & Hormone replacement therapy & Vitamin D \\
\hline \multirow[t]{2}{*}{ Age at first child birth } & & Calcium \\
\hline & & Selenium \\
\hline \multirow[t]{2}{*}{ Decrease risk } & Decrease risk & Dietary fiber \\
\hline & & Glycemic index \\
\hline Lactation & Fruits and vegetables & Soya based food \\
\hline \multirow[t]{2}{*}{ Body fatness (pre-menopausal) } & Physical activity & Total energy intake \\
\hline & & Milk and dairy products \\
\hline
\end{tabular}




\begin{tabular}{|c|c|c|c|c|c|}
\hline variables & Response: points & $\begin{array}{l}\text { Percentage } \\
\text { (number) }\end{array}$ & variables & response & $\begin{array}{c}\text { Percentage } \\
\text { (number) }\end{array}$ \\
\hline \multicolumn{6}{|c|}{ 1. Knowledge regarding Risk factor } \\
\hline \multirow[t]{3}{*}{ No Risk factor } & yes & $40.40(200)$ & Tobacco intake & Yes (1) & $30.10(148)$ \\
\hline & no & $59.60(295)$ & & No $(0)$ & $20.20(100)$ \\
\hline & & & & $\mathrm{DK}(0)$ & $49.89(247)$ \\
\hline \multirow[t]{3}{*}{ Advance Age } & Yes (1) & $30.3(149)$ & Alcohol intake & Yes (1) & $12(59)$ \\
\hline & No $(0)$ & $31.91(158)$ & & No $(0)$ & $16.2(80)$ \\
\hline & $\mathrm{DK}(0)$ & $37.97(188)$ & & $\mathrm{DK}(0)$ & $72(356)$ \\
\hline \multirow[t]{3}{*}{ Stressful life } & Yes (1) & $39.39(195)$ & Age of first conception (> $30 \mathrm{yrs}$ ) & Yes (1) & 20.10(99) \\
\hline & No $(0)$ & $10.71(53)$ & & No $(0)$ & $14.20(70)$ \\
\hline & $\mathrm{DK}(0)$ & $50.00(247)$ & & $\mathrm{DK}(0)$ & $65.70(325)$ \\
\hline \multirow[t]{3}{*}{ Gender susceptibility } & Yes (1) & $5.85(28)$ & Not having children & Yes (1) & $13.13(65)$ \\
\hline & No $(0)$ & $43.50(215)$ & & No $(0)$ & $30.30(150)$ \\
\hline & DK $(0)$ & $51.11(252)$ & & $\mathrm{DK}(0)$ & $56.56(280)$ \\
\hline \multirow[t]{3}{*}{ Family History of breast cancer } & Yes (1) & $50.50(250)$ & Repeated abortion & Yes $(0)$ & $29(144)$ \\
\hline & No $(0)$ & $21.21(105)$ & & No (1) & $10.2(50)$ \\
\hline & DK $(0)$ & $28.28(140)$ & & $\mathrm{DK}(0)$ & $60.8(300)$ \\
\hline \multirow[t]{3}{*}{ Dense breast } & Yes (1) & $35.35(174)$ & No breast feeding & Yes (1) & $14.54(72)$ \\
\hline & No $(0)$ & $12.52(62)$ & & No $(0)$ & $55.15(273)$ \\
\hline & $\mathrm{DK}(0)$ & $52.52(259)$ & & $\mathrm{DK}(0)$ & $30.30(150)$ \\
\hline \multirow[t]{3}{*}{ No relation with menstrual period } & Yes $(0)$ & $30.30(150)$ & Breast feeding for long period & Yes (1) & $29.89(148)$ \\
\hline & No (1) & $9.09(45)$ & & No $(0)$ & 19.39(96) \\
\hline & DK $(0)$ & $60.60(300)$ & & $\mathrm{DK}(0)$ & $50.70(251)$ \\
\hline \multirow[t]{3}{*}{ Early menarche (<11 yrs) } & Yes (1) & $7.07(35)$ & Vegetarian or non-vegetarian diet, or & Yes (1) & $36.5(181)$ \\
\hline & No $(0)$ & $22.22(110)$ & Excessive intake of Oily food & No $(0)$ & $19.19(95)$ \\
\hline & DK $(0)$ & $70.70(350)$ & & $\mathrm{DK}(0)$ & $59.14(219)$ \\
\hline \multirow[t]{3}{*}{ Late Menopause (> 55 yrs) } & Yes (1) & $17.17(84)$ & Breast cancer is a Contagious diseases & Yes $(0)$ & $5.85(29)$ \\
\hline & No $(0)$ & $20.2(100)$ & & No (1) & $43.0(213)$ \\
\hline & $\mathrm{DK}(0)$ & $62.82(311)$ & & $\mathrm{DK}(0)$ & $51.11(253)$ \\
\hline \multirow[t]{3}{*}{ Not having breast hygiene } & Yes (1) & $80.00(396)$ & Postmenopausal Obesity & Yes (1) & $11.00(54)$ \\
\hline & No $(0)$ & $10.10(50)$ & & No $(0)$ & $8.00(40)$ \\
\hline & DK $(0)$ & $10.00(49)$ & & $\mathrm{DK}(0)$ & $81(401)$ \\
\hline \multirow[t]{3}{*}{ Repeated Infection in the breast } & Yes $(0)$ & $10(49)$ & Regular physical exercise has preventive & Yes (1) & $2.42(12)$ \\
\hline & No (1) & $75(371)$ & effects & No $(0)$ & $52.12(258)$ \\
\hline & DK $(0)$ & $15.15(75)$ & & $\mathrm{DK}(0)$ & $45.45(225)$ \\
\hline \multirow[t]{3}{*}{ Trauma in the breast } & Yes $(0)$ & $50.50(250)$ & Radiation Exposure to breast & Yes (1) & $67.47(334)$ \\
\hline & No (1) & $12.0(59)$ & & No $(0)$ & $2.00(9)$ \\
\hline & $\mathrm{DK}(0)$ & $37.5(186)$ & & $\mathrm{DK}(0)$ & $30.72(152)$ \\
\hline \multirow[t]{4}{*}{ Always Wearing Brassiere } & Yes $(0)$ & $60.20(298)$ & Multi parity & Yes $(0)$ & 20.00(99) \\
\hline & No (1) & $20.00(50)$ & & No (1) & $7.00(35)$ \\
\hline & DK $(0)$ & $29.69(147)$ & & $\mathrm{DK}(0)$ & $73.00(361)$ \\
\hline & 2. Knowledge regard & symptoms of & east cancer & & \\
\hline \multirow[t]{3}{*}{ Painless lump in the Breast } & Yes (1) & $34.14(169)$ & Repeated Infection in the breast & Yes (1) & $58.58(290)$ \\
\hline & No $(0)$ & $28.48(141)$ & & No $(0)$ & $10.00(49)$ \\
\hline & DK $(0)$ & $37.37(185)$ & & $\mathrm{DK}(0)$ & $31.42(156)$ \\
\hline
\end{tabular}

Continued... 


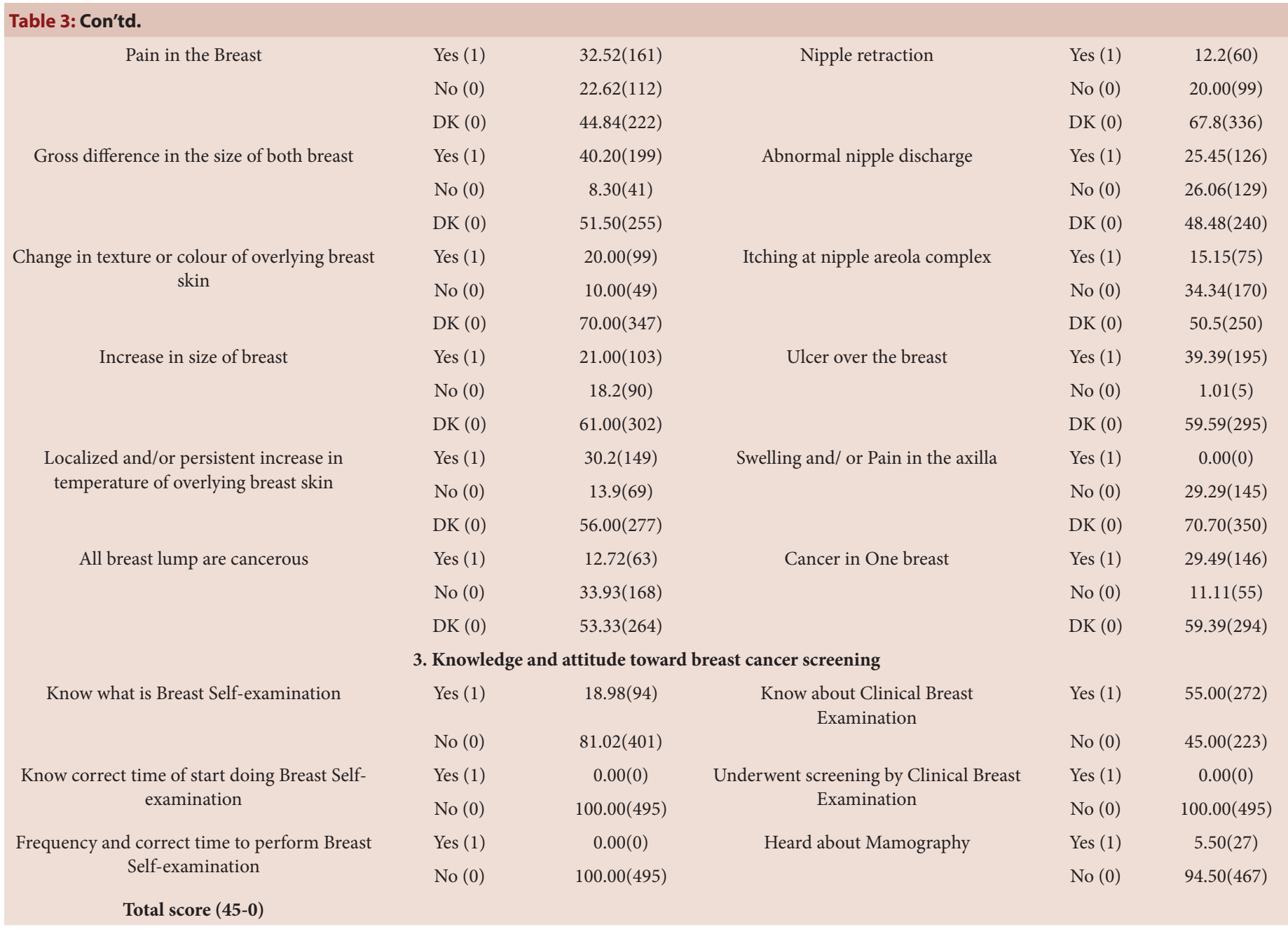

Foot note: DK: don’t know

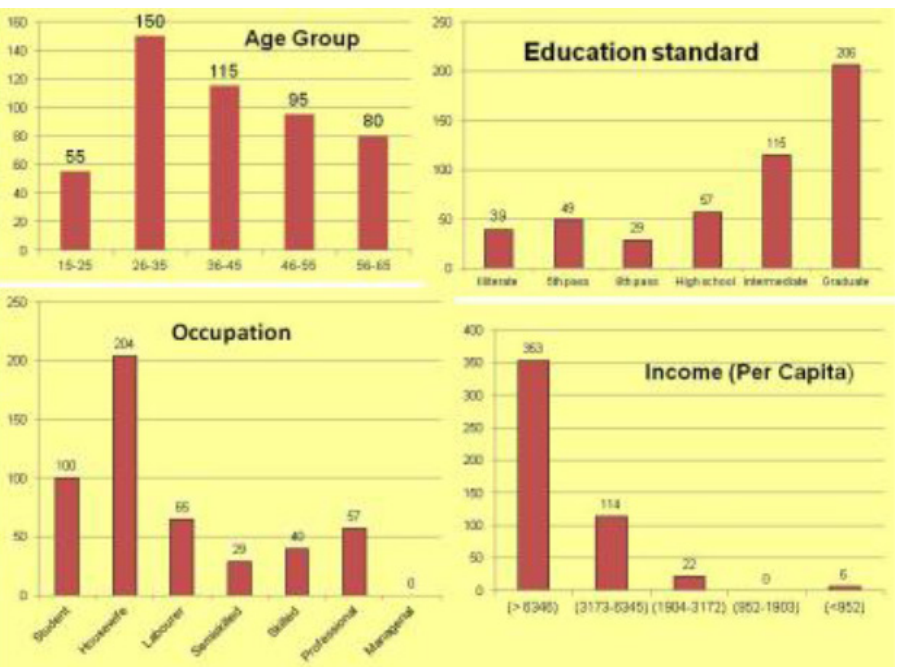

Figure 1: Proportion of participant in respective age group, their education standard, Occupation status and socioeconomic status (Modified G.B. Prasad 2016).

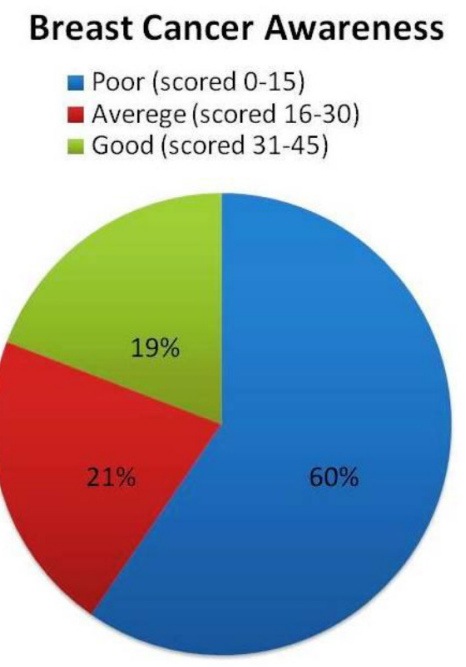

Figure 2: Breast cancer awareness level (based on self made scoring). 


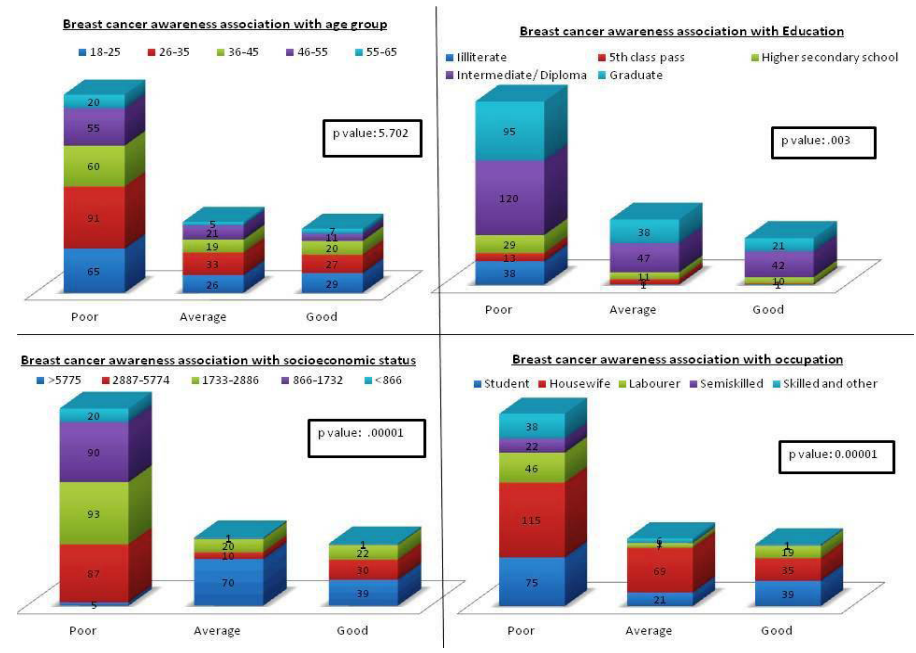

Figure 3: Correlation of Breast Cancer awareness level with age, education standard, Occupation status and Socio-economic status of participants (Modified B.G. Prasad 2016).

awareness level was found to be significantly associated with the education, occupation, urban and economical status (see Figure 3).

\section{DISCUSSION}

The mortality rates for breast cancer continue to rank the highest in India. ${ }^{1,2,15}$ Studies have proved that one-third of newly diagnosed cancer patients could experience increased survival if detected in early stage. ${ }^{18}$ There is an urgent need for spreading information and education on breast cancer and its early detection measures to reduce morbidity and mortality. ${ }^{19-26}$ Early detection will lead to earlier intervention, possible breast conserving surgery and personalizing adjuvant systemic therapy. ${ }^{25}$ There are various methods of early detection of breast cancer. These include: breast self-examination (BSE), clinical breast examination (CBE) and mammography screening.

BSE involves visualization and palpation of the breast by oneself for lumps, shape, texture, size and contour. The purpose of BSE is for a woman to learn the topography of her breasts, know how her normal breasts feel and be able to identify changes in them should they occur in the future. ${ }^{25}$

The presence of risk factor does not always invite the disease but they help in identifying women who would be benefitted from screening. Gupta et al. review of Indian studies (2005-2013) on breast cancer awarenes found no changes in the awareness level for symptoms, risk factor and screening methods over the 8 -year period. ${ }^{6}$

In our study it was seen that women often believed alcohol, tobacco, trauma to breast, repeated breast infection and brassier practices to be more important risk factors than reproductive history. ${ }^{26-29}$ The knowledge deficit of risk factors of breast cancer such as early age at menarche, late menopause, age at birth of first child, breast feeding practices prevents the women screening seeking behavior. By increasing the level of knowledge we can positively modulate their behavior toward screening behavior and practices. $^{26}$ The knowledge of modifiable risk factor (alcohol consumption, physical activity, weight control) will be beneficial as preventive measures adoptability in life. ${ }^{15}$ In our study majority (64.06 \%) participants was from urban area and we found a significant difference in the awareness level in urban versus rural population. We found $58 \%$ of identified trauma to breast and repeated infection in breast as a risk factor of breast cancer (vs 20\% in Somedutta et al. study at New Delhi). ${ }^{19}$ But these two are not considered as risk factors for breast cancer. ${ }^{14-16}$ We found knowledge of family history as a risk factor for breast cancer was high (50.5\%) similar to Khokhar et al. (58\%). ${ }^{23}$ While our study population have $60.4 \%$ urban population vs exclusive urban population (New Delhi) in Khokhar study. Alcohol consumption which is a well proven risk factor of Breast cancer was not responded to by most of our study participant (80\%), contrary to Ahuja et al. (85\%) study from Mumbai. ${ }^{24}$ We observed a response (0\%-15\%) for reproductive history and breast feeding practices as breast cancer risk factor was low similar to other. ${ }^{18-24}$ It was seen in our study that majority of the women $(12.72,63 / 495)$ did not associate a painless lump in the breast with breast cancer while $(39.39 \%, 195 / 495)$ thought that an ulcer over the breast (an advance stage of breast cancer) is a cancer. This shows that most of the women didn't recognize the most common presentation or the most common symptom (painless breast lump) of early breast cancer. These results are similar to those observed by other authors (Somdutta et al. from India, Okobiya et al. from Nigeria). ${ }^{19,30}$ None of the participants recognized a lump in the axilla as a possible symptom of breast cancer. Hence there is an urgent need for focused breast cancer awareness campaigns to educate the community on all the alarming sign of breast cancer.

The American College of Obstetricians and Gynecologists (ACOG) and the American Cancer Society recommend BSE once in a month beginning at the age of 20 years, one week after the menstrual flow. ${ }^{31}$ Many studies have suggested that monthly BSE is a reliable screening tool for breast cancer. ${ }^{32}$ The trends of breast cancer in developing countries is changing and the average age at diagnosis here is 10 years lower than that in western countries. ${ }^{5}$ Monthly BSE started from a younger age alerts women about abnormal changes in their breast so they can seek medical advice accordingly. ${ }^{25}$ Education of all women (irrespective of age) about monthly BSE promotion is an utmost demand of time. ${ }^{31,32}$

CBE which is performed by doctor or trained nurse practitioner, is important as it may detect lumps which are missed on BSE. ${ }^{33,35,36} \mathrm{CBE}$ may also detect those lumps which may be missed on conventional mammography if the affected area is not being specifically targeted in mammography. ${ }^{37}$ The recommendation of ACOG is to perform CBE annually for women over $40 \mathrm{yrs}$, every 3 years for women between 20 and $40 \mathrm{yrs}$ and more frequent examination for high risk patients. ${ }^{37,38}$ It is highly unfortunate that in our study no women were aware of correct time and frequency of performing BSE and CBE (our study and Somedutta et al. study). ${ }^{19}$ The World Health Organization stresses increasing CBE in all women attending primary health care or hospital. ${ }^{37}$ The governmental and non-governmental agencies working in the field of health in India, have been constantly trying to educate the women with initiatives like rallies, celebration of October month as breast cancer awareness month, regular health checkups, awareness cum screening camps etc. ${ }^{6,39-41}$ In developing countries, the major hindrances to increasing awareness are, poor access to treatment, inadequate knowledge of health professionals, (Breast Health Global Initiative 2010), lack of proper referral, financial constraints and abysmal involvement of media (television / newspaper/ social media). ${ }^{42,43}$ The Indian media has traditionally focusing on spreading awareness about the ill effects of tobacco use. ${ }^{44}$ They should also highlight the issues related to breast cancer. ${ }^{45}$

Literacy is an important factor towards accepting breast cancer screening methods. But educational interventions, the attitude and practices regarding breast cancer are still poor because of the non-compliant attitude of women toward breast cancer screening, fear of stigma, discrimination denial within community and distrust in the health system. ${ }^{45}$

It is suggested that hospital based education, BSE and CBE for all female patients should be mandatory at all health care centers. Their hospital visit should be used as an opportunity to educate them for breast cancer and correct method of BSE. In underdeveloped and developing countries because of paucity of funds and trained manpower we may target 
women for screening in the age group. BSE is the best screening tool for breast cancer among all age group women. The community based outreach program including frequent camps for CBE by experts and hands on training on BSE may reduce the burden of breast cancer in India and improve the mortality and morbidity of this disease.

\section{CONCLUSION}

To conclude this study showed a wide knowledge gap about Breast cancer symptoms, risk factor and methods of early detection. Mammography screening and population-based awareness programme, together with improved treatment, may contribute to mortality reduction in breast cancer. In our study participants literacy levels was higher as this study was institution based predominately involve urban population. The findings of study may not be generalized across the country.

\section{ACKNOWLEDGEMENT}

We give our heartfelt thanks to our esteemed Director Sir, Dr. Nitin M. Nagarkar and Prof and Head Sarita Agrawal, Dept of Obstetrics and Gynaecology for their support and blessings to carry out this work.

\section{CONFLICT OF INTEREST}

The authors declare no conflict of interest.

\section{ABBREVIATIONS}

ACOG: American College of Obstetricians and Gynecologists; AICR: American Institute of Cancer Research; BSE: Breast Self Examination; CBE: Clinical Breast Examination; IARC: International Agency for research on Cancer; NCCP: National Cancer Control Program; OCP: Oral Contraceptive Pill; WCRF: World Cancer Research Fund.

\section{SUMMARY}

The knowledge, attitude and practices regarding breast cancer were studied among women of reproductive age group attending the outdoor clinics of a Medical college and hospital. 500 women were enrolled for this cross sectional study. The findings showed that a wide knowledge gap existed in the area of breast cancer symptoms, risk factors and screening methods, among the study subjects. Hence CBE and training for BSE can be introduced as a mandatory policy for women attending outdoor clinics in hospitals.

\section{REFERENCES}

1. Trends of Breast Cancer in India [Internet]. [cited 2018 Nov 1]. Available from: http://www.breastcancerindia.net/statistics/trends.html

2. Gupta S. Breast cancer: Indian experience, data and evidence. South Asian J Cancer. 2016;5(3):85-6.

3. Bridges JFP, Anderson BO, Buzaid AC, Jazieh AR, Niessen LW, Blauvelt BM, et al. Identifying important breast cancer control strategies in Asia, Latin America and the Middle East/North Africa. BMC Health Serv Res. 2011;11(1):227. [Internet]. BioMed Central [cited 2018 Nov 1] Available from: http://www.ncbi.nlm.nih.gov/ pubmed/21933435

4. Three-Year Report of Population Based Cancer Registries Incidence and Distribution of Cancer (Report of 25 PBCRs in India) [Internet]. 2009 [cited 2018 Nov 1]. Available from: http://www.pbcrindia.org/

5. Ferlay J, Soerjomataram I, Ervik M, Dikshit R, Eser S, Mathers C, et al. Estimated Cancer Incidence, Mortality and Prevalence Worldwide in 2012. IARC Cancer Base. 2012:1(11).

6. Gupta A, Shridhar K, Dhillon PK. A review of breast cancer awareness among women in India: Cancer literate or awareness deficit?. European Journal of Cancer. 2015;51(14):2058-66.

7. Sharma K, Costas A, Shulman LN, Meara JG. A systematic review of barriers to breast cancer care in developing countries resulting in delayed patient presentation. J Oncol. 2012;2012.

8. Pati S, Hussain MA, Chauhan AS, Mallick D, Nayak S. Patient navigation pathway and barriers to treatment seeking in cancer in India: a qualitative inquiry. Cancer Epidemiol. 2013;37(6):973-8.
9. Torre L, Bray F, Siegel RL, Ferlay J, Lortet-Tieulent J, Jemal A. Global cancer statistics, 2012. CA Cancer J Clin. 2015;65(2):87-108.

10. Leong SP, Shen ZZ, LiuTJ, Agarwal G, TajimaT, Paik NS, et al. Is breast cancer the same disease in Asian and western countries?. World J Surg. 2010;34(10):2308-24.

11. Madhu B, Ashok NC, Balasubramanian S. A multinomial logistic regression analysis to study the influence of residence and socioeconomic status on breast cancer incidences in southern Karnataka. Int J Math Stat Invention. 2014;2(5):01-8.

12. Rath GK, Gandhi AK. National cancer control and registration program in India Indian J Med Paediatr Oncol. 2014;35(4):288-90.

13. Shaikh Z, Pathak R. Revised Kuppuswamy and B G Prasad socio-economic scales for 2016. Int J Community Med Public Health. 2017;4(4):997-9.

14. Keeping the science current Breast Cancer 2010 Report Food, Nutrition, Physical Activity and the Prevention of Breast Cancer [Internet]. [cited 2018 Nov 1]. Available from: https://www.wcrf.org/sites/default/files/Breast-Cancer-2010-Report.pdf

15. Lakshmi R, Vijayalakshmi S, Raju A, Joy TM. Assessment of various risk factors of breast cancer. Int J Pharm Sci. 2013;5(Suppl 4):675-8.

16. International Agency for Research on Cancer. Monograph on the Evaluation of Carcinogenic Risks to Humans. Hormonal Contraception and Post-Menopausal Hormonal Therapy. Lyon, France: IARC. 1999;72:67-109.

17. López-Gómez M, Malmierca E, de Górgolas M, Casado E. Cancer in developing countries: the next most preventable pandemic. The global problem of cancer. Crit Rev Oncol Hematol. 2013;88(1):117-22.

18. Yadav $\mathrm{P}$, Jaroli DP. Breast cancer: awareness and risk factors in collegegoing younger age group women in Rajasthan. Asian Pac J Cancer Prev. 2010;11(2):319-22.

19. Somdatta P, Baridalyne N. Awareness of breast cancer in women of an urban resettlement colony. Indian J Cancer. 2008;45(4):149-53.

20. Gangane N, Ng N, Sebastián MS. Women's Knowledge, Attitudes and Practices about Breast Cancer in a Rural District of Central India. Asian Pac J Cancer Prev. 2015;16(16):6863-70.

21. Sharma P, Ganguly E, Nagda D, Kamaraju T. Knowledge, attitude and preventive practices of South Indian women towards breast cancer. Health Agenda 2013;1(1):72-4.

22. Rao R, Suma N, Nair NS, Kamath VG. Acceptability and effectiveness of a breast health awareness program for rural women in India. Indian J Med Sci. 2005; 59:398-402.

23. Puri S, Mangat C, Bhatia V, Kalia M, Sehgal A, Kaur A. Awareness Of Risk Factors And Aspects of Breast Cancer Among North Indian Women. The Internet Journal of Health. 2008. [cited 2018 Nov 1]. Available from: https://print.ispub. com/api/0/ispub-article/7590

24. Khokhar A. Level of awareness regarding breast cancer and its screening amongst Indian teachers. Asian Pac J Cancer Prev. 2009;10(2):247-50.

25. Ahuja S, Chakrabarti N. To Determine The Level Of Knowledge Regarding Breast Cancer And To Increase Awareness About Breast Cancer Screening Practices Among A Group Of Women In A Tertiary Care Hospital In Mumbai, India. The Internet Journal of Public Health. 2009;1. [Internet]. [cited 2018 Nov 1]. Available from: https://print.ispub.com/api/0/ispub-article/10062

26. Senkus E, Kyriakides S, Ohno S, Penault-Llorca F, Poortmans P, Rutgers E, et al Primary breast cancer: ESMO Clinical Practice Guidelines for diagnosis, treatment and follow-up. Ann Oncol. 2015;26(Suppl 5):v8-30.

27. Garg P, Bansal M, Garg M, Arora B. Creating awareness about the painless nature of early breast cancer lump is important in low-income countries. Breast J. 2010;16(1):101-2.

28. Anderson B, Shyyan R, Eniu A, Smith RA, Yip CH, Bese NS, et al. Breast cancer in limited-resource countries: an overview of the Breast Health Global Initiative 2005 guidelines. Breast J. 2006;12(Suppl 1):S3-15

29. Gaudet MM, Gapstur SM, Sun J, Diver WR, Hannan LM, Thun MJ. Active smoking and breast cancer risk: original cohort data and meta-analysis. J Nat Cancer Inst. 2013;105(8):515-25.

30. Bagnardi V, Rota M, Botteri E, Tramacere I, Islami F, Fedirko V, et al. Light alcohol drinking and cancer: a meta-analysis. Ann Oncol. 2012;24(2):301-8.

31. Hackshaw AK, Paul EA. Breast self-examination and death from breast cancer: a Meta-Analysis. Br J Cancer. 2003;88(7):1047-53

32. ACOG Statement on Revised American Cancer Society Recommendations on Breast Cancer Screening - ACOG [Internet]. [cited 2018 Nov 1]. Available from: https://www.acog.org/About-ACOG/News-Room/Statements/2015/ACOGStatement-on-Recommendations-on-Breast-Cancer-Screening

33. Okobia MN, Bunker $\mathrm{CH}$, Okonofua FE, Osime U. Knowledge, attitude and practice of Nigerian women towards breast cancer: A cross sectional study. World J Surg Oncol. 2006;21(1):4-11.

34. Philip J, Harris WG, Flaherty C, Joslin CA, Rustage JH, Wijesinghe DP. Breast self-examination: clinical results from a population-based prospective study. Br J Cancer. 1984;50(1):7-12.

35. Senkus E, Kyriakides S, Ohno S, Penault-Llorca F, Poortmans P, et al. ESMO Guidelines Committee. Primary breast cancer: ESMO Clinical Practice Guidelines for diagnosis, treatment and follow-up. Ann Oncol. 2015;26(Suppl 5):v8-30. 
36. Final Update Summary: Breast Cancer: Screening - US Preventive Services Task Force [Internet]. [cited 2018 Nov 1]. Available from: https://www.uspreventiveservicestaskforce.org/Page/Document/UpdateSummaryFinal/breastcancer-screening1

37. Provencher L, Hogue JC, Desbiens C, Poirier B, Poirier E, Boudreau D, et al. Is clinical breast examination important for breast cancer detection?. Curr Oncol. 2016;23(4):e332-9.

38. Oeffinger KC, Fontham ETH, Etzioni R, Herzig A, Michaelson JS, Shih YCT, et al. Breast Cancer Screening for Women at Average Risk: 2015 Guideline Update from the American Cancer Society. JAMA. 2015;314(15):1599-614.

39. Breast Cancer Awareness Month | National Health Portal Of India [Internet]. [cited 2018 Nov 1]. Available from: https://www.nhp.gov.in/breast-cancer-awareness-month_pg.

40. Varghese C. 50 Years of Cancer Control in India 48 cancer prevention and contro in india [Internet]. [cited 2018 Nov 1]. Available from: https://mohfw.gov.in/sites/ default/files/Cancer Prevention And Control In India.pdfCharts Bin, com, viewed on $25^{\text {th }}$ September, 2011, http://chartbin.com/view/252
41. Beproactive: Indian flyers welcome breast cancer awareness campaign, Health News, ET HealthWorld [Internet]. [cited 2018 Nov 1]. Available from: https:// health.economictimes.indiatimes.com/news/industry/indian-flyers-welcomebreast-cancer-awareness-campaign/61264433India.gov.in

42. Mandrik O, Ekwunife OI, Zielonke N, Meheus F, Severens JL, Lhachimi SK. What determines the effects and costs of breast cancer screening?. A protocol of a systematic review of reviews. Syst Rev. 2017;6(1):122.

43. Murthy NS, Kishore C, Rath GK. Burden of Cancer and Projections for 2016, Indian Scenario: Gaps in the Availability of Radiotherapy Treatment Facilities. Asian Pacific Journal of Cancer Prevention. 2008;9(4):671-7.

44. The cigarettes and other tobacco products (prohibition of advertisement and regulation of trade and commerce [Internet]. [cited 2018 Nov 1]. Available from: https://indiacode.nic.in/bitstream/123456789/2053/1/200334.pdf

45. Pramesh C, Badwe RA, Borthakur BB, Chandra M, Raj EH, et al. Delivery of affordable and equitable cancer care in India. Lancet Oncol. 2014;15(6):e223-33.

Cite this article : Singh S, Pal A, Srivastava NK, Thakur P. Level of Awareness and Practices of Women Regarding Breast Cancer in Chhattisgarh, India: An Institution Based Survey. Int J Med Public Health. 2018;8(4):145-51. 


\section{Age Married/ unmarried Religion \\ \begin{tabular}{l|l|l} 
Education & occupation & Economic status (family income)
\end{tabular}}

\begin{tabular}{l|l|l|l}
$\mathbf{1}$ & Do you know about breast cancer? & Yes & No
\end{tabular}

2 If yes where you get the information about breast cancer (tick appropriate option): News paper/ Television/ Neighbors or relatives/ Hording in the city/ clinician information?

3 Which of the following is a symptom of breast cancer?

$\begin{array}{ll}\text { a. Lump in the breast } & \text { Yes No }\end{array}$

b. Difference in the size of both breast

Yes No

c. Swelling in the breast

Yes No

d. Change in the shape of breast

Yes No

e. Pain in the breast

Yes No

f. Discharge from the breast

Yes No

g. Change in skin colour or texture over the breast

Yes No

4 Having a lump in the breast means you have a breast cancer?

Yes No

5 If there is a lump in the breast and found to be non-cancerous on

Yes No investigation at present, this lump may turn to be malignant in future?

6 Breast cancer is a disease of old age?

Yes No

7 Can man also have a breast cancer?

Yes No

8 Is the breast cancer spread to other person by contact?

Yes No

9 Is the breast cancer is familial?

Yes No

10 Is the breast cancer is preventable disease?

Yes No

11 Is the breast cancer is related to menstrual period in female Yes No If yes what is the relation?

12 Is the breast cancer is related with age of female first conception If yes what is the relation?

13 Is the breast cancer is related to the breast feeding practices? If yes what is the relation

14 Is wearing wired brassier cause breast cancer?

Yes No

Yes No

Yes No

15 What do you think if a female has relative (mother/ sister/ grandmother/ Yes No 
granny) suffered from breast cancer than, this female has high risk of breast cancer development?

16 What do you think if a male/female having a family member (mother/ father/ brother/ sister/ grandfather/ grandmother) suffered from a cancer other than the breast cancer than that male/ female has a risk of breast cancer?

17 Is having a cancer in one breast increases the risk of breast cancer in other breast also (despite of complete treatment of breast cancer)

18 Is there is a relation between breast cancer and other cancer of female? if yes : relation is with which cancer ovarian cancer Uterine cancer

19 Having a breast cancer means patient is going to die very soon?

Yes No

20 Is the breast cancer is completely curable?

21 Can you prevent the breast cancer completely?

Yes No

22 Can you prevent the risk factor of breast cancer by changing your life style?

If yes what are that (tick the appropriate answers)

Having a baby before 30 yrs of age

Breast feeding the baby at least 2 years of age

Avoidance of alcohol

Avoidance of smoking

Having physical exercise

23 Are you aware of treatment modalities for breast cancer? If yes tick appropriate one

Operation

Radiotherapy

Chemotherapy

all

24 Is there is only one way of surgery for breast cancer: that is complete removal of cancerous breast?

25 Do you think the body image of female get distorted after operation of breast cancer?

26 Do you know that even after complete removal of breast tissue there are methods to restore the size of breast by various surgical methods

27 Do you know that there are new techniques for early detection of breast $\quad$ Yes No cancer, so that complete treatment can be done in time?

If yes what are that

a. Breast self examination

b. Clinical breast examination

c. Mamography (x ray of breast) 
d. Ultrasonography of breast

28 Do you know that all females should do the self breast examination every month after 20 years of age?

If yes what is the best time to perform it

a. Before the start of menstrual period

b. At the time of menses

c. After the menstruation is over

29 Do you know that all females should go for clinical breast examination every six month after 40 years of age for early detection of breast cancer?

30 Do you know that after 40 yrs of age every female is advised for mammography (x-ray of breast) once in a year for early detection of breast cancer?

31 Do you think that taking a tissue from breast lump will spread the tumor in the body?

Yes No 